\title{
EFICIÊNCIA DE EXTRATORES DE FÓSFORO PARA UM SOLO ADUBADO COM FOSFATOS E CULTIVADO COM ARROZ
}

\author{
J.S.DE HOLANDA'; E.C. BRASIL'; A.A.C. SALVIANO'; M.C.S.CARVALHO'; M.R.L. RODRIGUES'; \\ E.MALAVOLTA ${ }^{2}$ \\ 1 Depto. de Ciéncia do Solo, ESALQ/USP, C.P. 9 - CEP 13.418-900. Pinacicaba - SP \\ 2 CENA/USP. C.P. 96. CEP 13.400-000. Pinacicaba - SP
}

RESUMO - Visando comparar a eficiência de extratores quimicos e isotópico na avaliação da disponibilidade de fosforo no solo, foi condurido um experimento em casa de vegetação com Latossolo Vermelho-Amarelo. Foram realizados dois cultivos anteriores, com aplicação de fosfatos somente no primeiro. Os fosfatos usados foram: superfosfato simples, termofosfato Yoorin, Fosmag, fosfatos de Araxa e de Gafsa, nas doses de 50 e 150 mg.kg-1 terra. Neste experimento, terceiro cultivo, foram avaliados os extratores: Mehlich 1, Bray-1, resina e valor "E". As maiores correlações entre P-extraível do solo com produçăo de matéria seca e absorção de $P$ pelo arroz foram apresentadas pelos extratores Bray-1 $(r=0,92)$ e resina $(r=0,91)$. O fósforo determinado pelo extrator Mehlich-1 somente apresentou alta correlação com os parâmetros da planta $(r=0,96)$ quando da exclusão dos tratamentos com fosfato de Araxá. Os resultados de fósforo extraído pelo Bray-1 e resina foram altamente correlacionados entre si $(r=0,98)$.

Descritores: P-solo; P-absorvido; extratores de f6sforo; fosfatos solúveis; fosfatos naturais, arroz, Oryza sativa

\section{THE EFFICIENCY OF PHOSPHORUS EXTRACTANTS FOR A SOIL TREATED WITH PHOSPHATIC FERTILIZERS AND CULTIVATED TO RICE}

\begin{abstract}
In order to assess the efficiency of several extracting procedures for soil phosphorus a pot experiment was carried out using a Red Yellow Latosol. Previously two successive croppings had been made, $P$ fertilizers being applied only in the first one. The following products were used at the rates of 50 and 150 mg.kg ${ }^{\circ}$ soil: Yoorin (thermo-phosphate), "Fosmag", Araxa and Gafsa rock phosphates. Mehlich-1, Bray-1, anion exchange resin, and isotopic dilution (" $E$ " value) methods were used as extracting procedures of available soil-P. The closest correlations between soil - $P$ and either dry matter yield or phosphorus taken up by the rice plant were found with $B$ ray $-1(r=$ $0.92)$ and resin $(r=0.91)$. Phosphorus determined by Mehlich-1 extracting solution showed high correlation with plant parameters $(r=0.96)$ only when the Araxa rock phosphate treatments were excluded from the calculation. High correlations ( $r=0.98$ ) were found between the values corresponding to Bray- 1 and resin methods.
\end{abstract}

Key words : Available soil-P; uptaken-P; extractants-P; rock phosphate; soluble-phosphate, rice, Oryza sativa

\section{INTRODUÇÃO}

A carência de fósforo em solos brasileiros associada a sua baixa mobilidade e alta afinidade por minerais de ferro e alumínio torna o solo um "competidor da planta" pelo elemento e faz com que o mesmo seja o macronutriente mais usado em adubação.

Diversos são os métodos utilizados para avaliação do fósforo no solo, apresentando diferentes capacidades de extração que nem sempre se correlacionam bem com o absorvido pelas plantas (RAIJ, 1991; SILVA \& BRAGA, 1992). No
Brasil, sob condições de fertilidade natural ou quando da adubação com fosfatos solúveis, os métodos de avaliação em uso estimam razoavelmente a disponibilidade de fósforo para as plantas (CABALA - ROSAND \& SANTANA, 1981; GALRÃO \& VOLKWEISS, 1981). Por outro lado, extratores com tendência para liberação seletiva do fósforo ligado a ferro e alumínio fornecem melhor avaliação do fósforo disponivel para as plantas, principalmente quando se usam fosfatos naturais (CABALA-ROSAND \& SANTANA, 1981; TANAKA et al., 1981; GRANDE et al., 1986; BARBOSA FILHO et al., 1987; RAIJ, 1991; 
STEFANUTTI, 1991). O fósforo trocável do solo, avaliado pelo seu iśtopo radioativo $\mathrm{P}^{32}$, com determinação do valor " $E$ ", dependendo da condição de equilíbrio, pode se correlacionar bem com o absorvido pela planta (MURAOKA, 1991; STEFANUTTI, 1991; CRISANTO \& SUTTON, 1973; BOWMAN et al., 1978; CABALA-ROSAND \& WILD, 1982).

O presente trabalho teve como objetivos avaliar a eficiência de extratores químicos e isotópico de fósforo do solo, relacionando o Pextraído com o P-absorvido e com a produção de matéria seca pela cultura do arroz.

\section{MATERIAL E MÉTODOS}

$O$ experimento foi conduzido em casa de vegetação, no Centro de Energia Nuclear na Agricultura -CENA/USP, utilizando-se amostras da camada superficial $(0-20 \mathrm{~cm})$ de solo classificado como Latossolo Vermelho-Amarelo, município de São Pedro(SP).

Foi utilizado o arroz como planta teste, correspondendo ao terceiro cultivo de uma rotação arroz-feijão. No primeiro cultivo, foram aplicadas

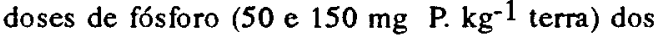
seguintes adubos fosfatados: superfosfato simples, termofosfato Yoorin magnesiano, Fosmag, fosfato de Araxá e fosfato de Gafsa. A acidez do solo foi inicialmente corrigida, através da aplicação de calcário e em todos os cultivos foram efetuadas adubações com nitrogênio, potássio, boro e zinco. Antes da implantação do primeiro cultivo, as amostras de terra sem adubação fosfatada, apresentaram as seguintes características químicas: matéria orgânica $28 \mathrm{~g} . \mathrm{kg}^{-1} ; \mathrm{pH}\left(\mathrm{CaCl}_{2} 0,005 \mathrm{~mol} . \mathrm{L}\right.$

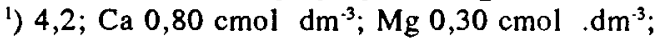

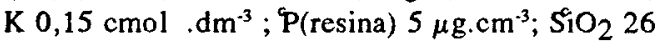
g.kg ${ }^{-1} ; \mathrm{Al}_{2} \mathrm{O}_{3}^{\mathrm{c}} 41$ g.kg $; \mathrm{Fe}_{2} \mathrm{O}_{3} 21$ g.kg.1.

A parcela experimental consistiu de vasos contendo $2 \mathrm{~kg}$ de terra. $O$ delineamento experimental foi inteiramente casualizado, com três repetições. Antes da semeadura do arroz, terceiro cultivo, efetuou-se aplicação de calcário dolomítico $(30 \% \mathrm{CaO}, 10 \% \mathrm{MgO}$ e PRNT $=100 \%)$, na forma de suspensão, contendo $100 \mathrm{~g}$ do produto por litro. A suspensão foi aplicada nas doses de $35 \mathrm{ml}$ por vaso, exceto nos tratamentos com termosfosfato Yoorin (150 mg de P. $\mathrm{kg}^{-1}$ ) e fosfato de Gafsa (150 g de P. $\mathrm{kg}^{-1}$ ) que receberam 25 e $30 \mathrm{ml}$ por vaso, respectivamente.

O fósforo residual do solo foi analisado através de extração pelos métodos de Melich 1 (EMPRESA BRASILEIRA DE PESQUISA AGROPECUÁRIA-EMBRAPA, 1979), Bray-1 (BRAY \& KURTZ, 1945), resina trocadora de íons (RAIJ \& QUAGGIO, 1983) e pela técnica de diluição isotópica (Valor E), seguindo-se a metodologia descrita por LARSEN (1952).

A semeadura do arroz foi realizada utilizando-se 10 sementes por vaso, deixando-se posteriormente duas plantas. Efetuou-se uma adubação básica de plantio ${ }^{1}$, comum a todos os tratamentos, com $356 \mathrm{mg}$ de $\mathrm{NH}_{4} \mathrm{NO}_{3} ; 208 \mathrm{mg}$ de $\mathrm{KCl} ; 11,8 \mathrm{mg}$ de $\mathrm{H}_{3} \mathrm{BO}_{3} ; 20 \mathrm{mg}$ de $\mathrm{CuSO}_{4} ; 149$ $\mathrm{mg}$ de $\mathrm{MnSO}_{4} ; 2 \mathrm{mg}$ de $\mathrm{NH} \mathrm{MoO}$. Após o plantio foram realizadas três adubaç̧̃óes đe cobertura com nitrogênio e potássio, em intervalos de quinze dias, fornecendo-se $100 \mathrm{mg}$ de cada elemento por vaso em cada aplicação.

Durante a condução do ensaio, o solo foi mantido com umidade em torno de $60 \%$ da capacidade de campo através de regas diárias.

Após 99 dias da semeadura, as plantas foram colhidas e colocadas em estufa a $70^{\circ} \mathrm{C}$, para determinação do peso da matéria seca da parte aérea e conteúdo de fósforo total nos tecidos vegetais, de acordo com metodologia descrita por MALAVOLTA et al.

A eficiência dos extratores foi avaliada através de análise de regressão, empregando-se como parâmetros de avaliação da disponibilidade do fósforo a quantidade de $\mathrm{P}$-acumulado na parte aérea e a produção de matéria seca de arroz, correlacionando-os com o fósforo extraído do solo pelos diferentes extratores. Realizou-se, também, análise de correlação entre os extratores.

\section{RESULTADOS E DISCUSSÃO}

A capacidade de recuperação do fósforo aplicado no solo foi bem diferenciada entre os extratores usados, variando a média na seguinte ordem de valores: valor " $E$ " > Mehlich $1>$ Bray$1>$ resina. De um modo geral, as quantidades de fósforo extraídas pelos diferentes métodos variaram em termos relativos, em função de doses e fontes de fósforo aplicadas (TABELA 1). Embora se diferenciem quanto à capacidade de extração, o uso 


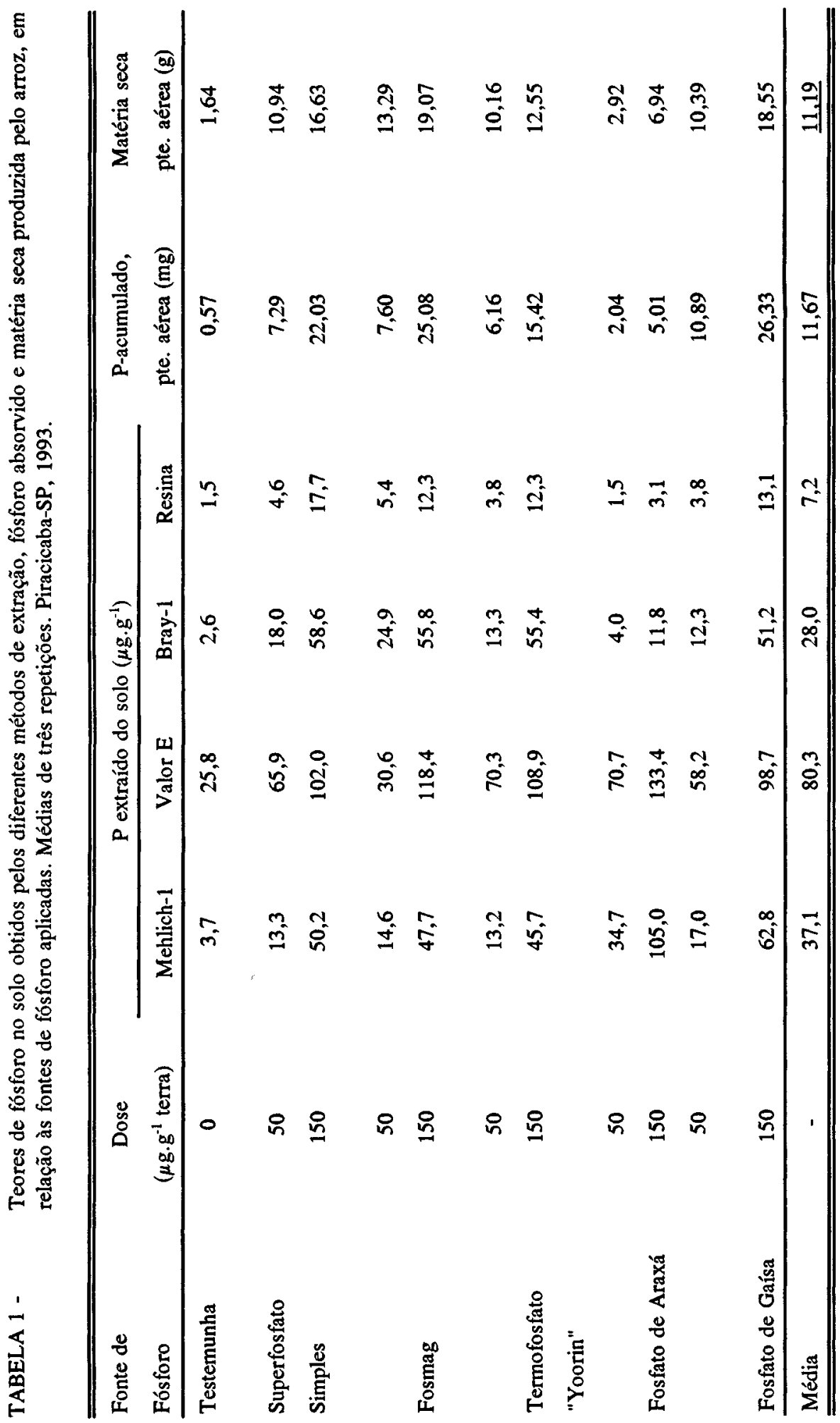


de diferentes métodos na análise de fósforo leva a resultados não comparáveis em seus valores absolutos devido à influência de condições particulares de cada técnica de determinação (RAIJ, 1978; SILVA \& BRAGA, 1992).

A produção de matéria seca pela parte aérea das plantas de arroz e a quantidade de fósforo nela contida apresentaram maior correlação com o fósforo residual do solo avaliado pelos extratores Bray-1 e resina (Figuras 1 e 2). Estes resultados confirmam vários trabalhos de pesquisa e se fundamentam nas reações que ocorrem para remoção de fósforo do solo. O extrator Bray-1 atua eficientemente através do íon fluoreto complexando os cátions ligados ao fósforo nas formas P-Al e P$\mathrm{Fe}$, predominantes em solos ácidos tropicais (SILVA \& BRAGA, 1992) e é uma exceção entre os extratores ácidos, por não dissolver apatitas (RAIJ, 1978). O método da resina se comporta bem por extrair formas lábeis de fósforo em processo similar ao das raízes das plantas, expressando o equilibrio entre P-lábil e P-solução (RAIJ, 1991;

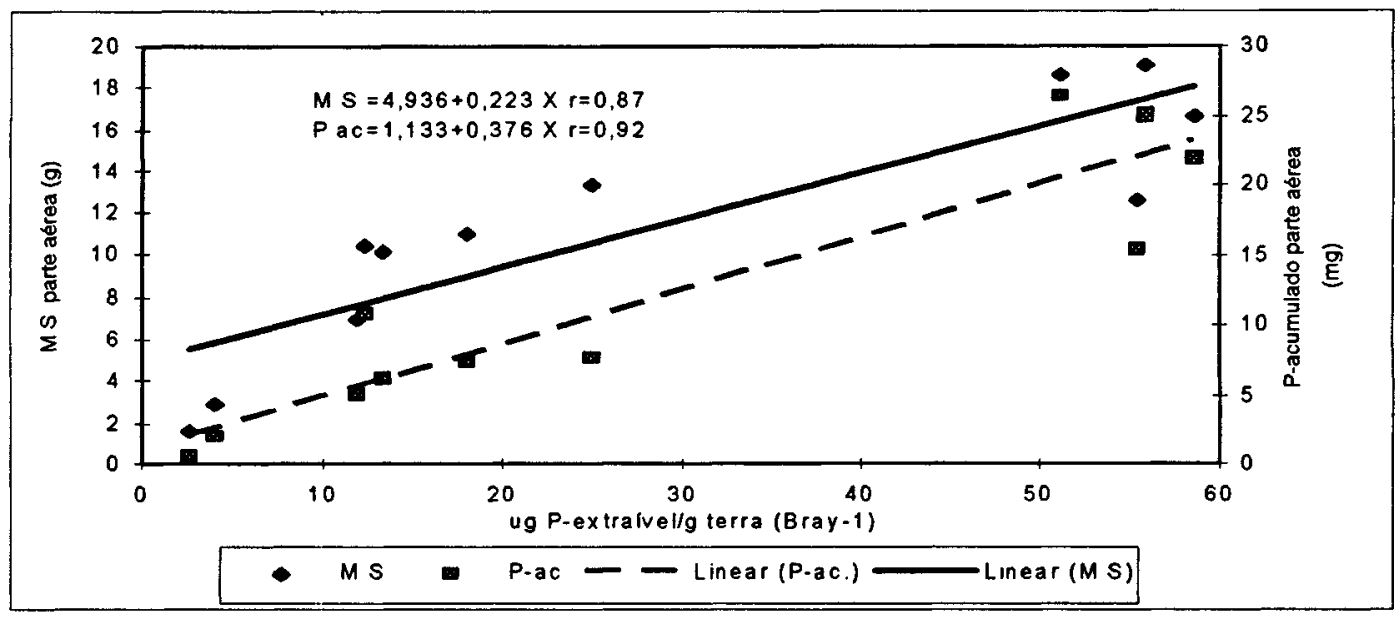

Figura 1- Relação entre produção de matéria seca (M.S) e fósforo acumulado (P-ac.) pela parte aérea do arroz com o fósforo disponivel no solo, determinado pelo extrator Bray-1.

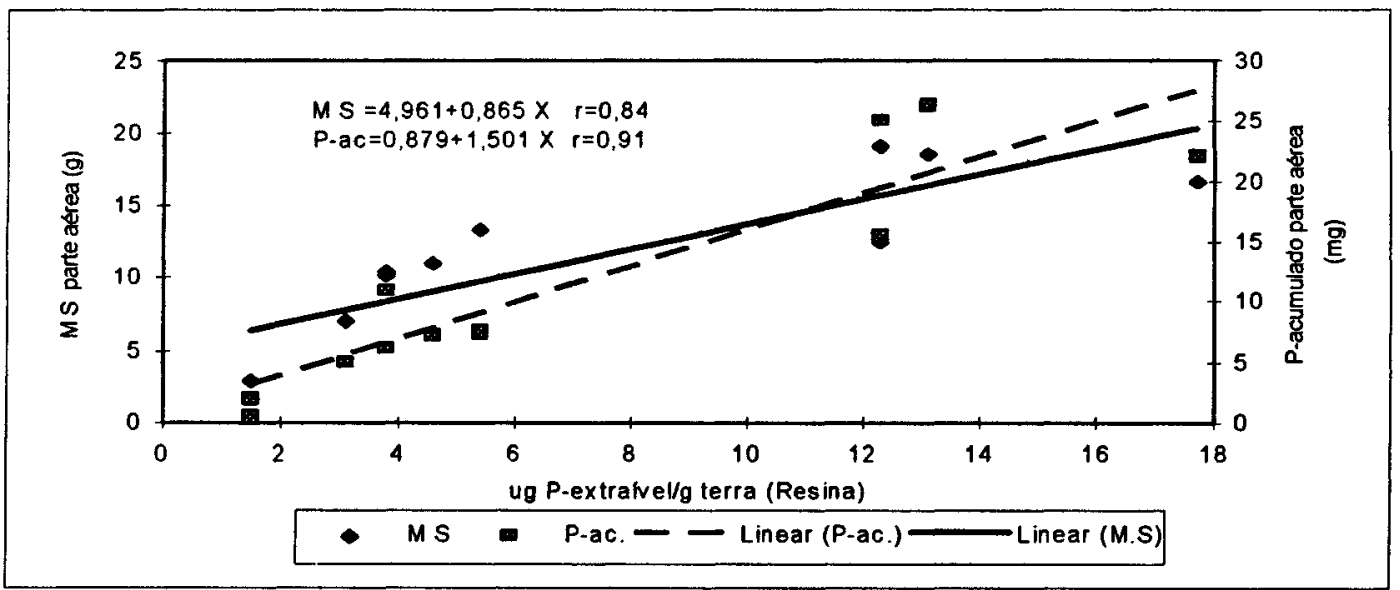

Figura 2- Relação entre produção de matéria seca (M.S) e fósforo acumulado (P-ac.) pela parte aérea do arroz com o fósforo disponivel no solo, determinado pelo método da resina. 
STEFANUTTI, 1991; BARBOSA FILHO $e t$ al., 1987; GRANDE et al., 1986). A resina, tendo menor influência sobre as formas não disponíveis de P-Ca no solo, apresenta vantagens, quando sob condições de adubação com fosfatos naturais (CABALA-ROSAND \& SANTANA, 1981), onde os extratores ácidos são ineficientes (RAIJ et al.,1984).

Os resultados obtidos pelo valor " $E$ " apresentaram baixa correlação entre os teores de $P$ extraídos e a produção de matéria seca ou as quantidades de fósforo contidas na parte aérea das plantas de arroz (Figura 3). Esses resultados discordam de alguns trabalhos encontrados na literatura, onde foram obtidos altos coeficientes de correlação entre o P do solo com o P absorvido pelas plantas (CABALA \& WILD, 1982; BOWMAN et al., 1978; CRISANTO \& SUTTON, 1973). Essa técnica, teoricamente apresenta a estimativa real do $\mathbf{P}$ disponível para as plantas pois, representa a quantidade de $P$ trocável na superfície das partículas e na solução do solo, que é extraída utilizando-se o

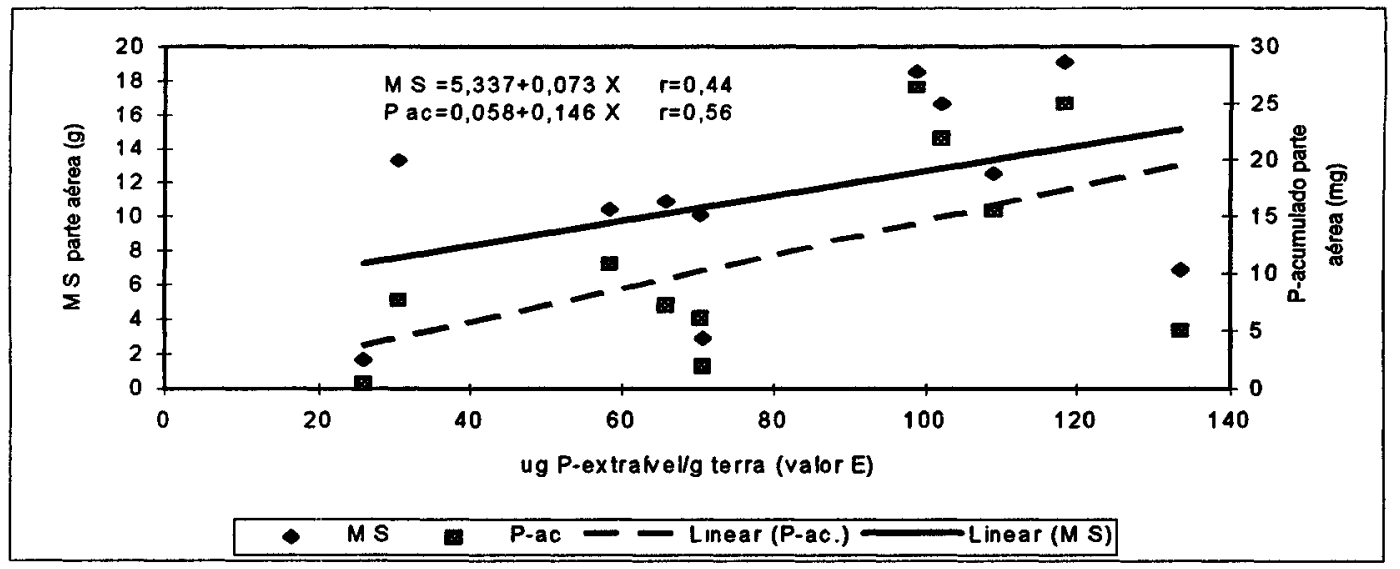

Figura 3- Relação entre produção de matéria seca (M.S) e fósforo acumulado (P-ac.) pela parte aérea do arroz com o fósforo disponivel no solo, determinado pelo método isotópico (valor E).

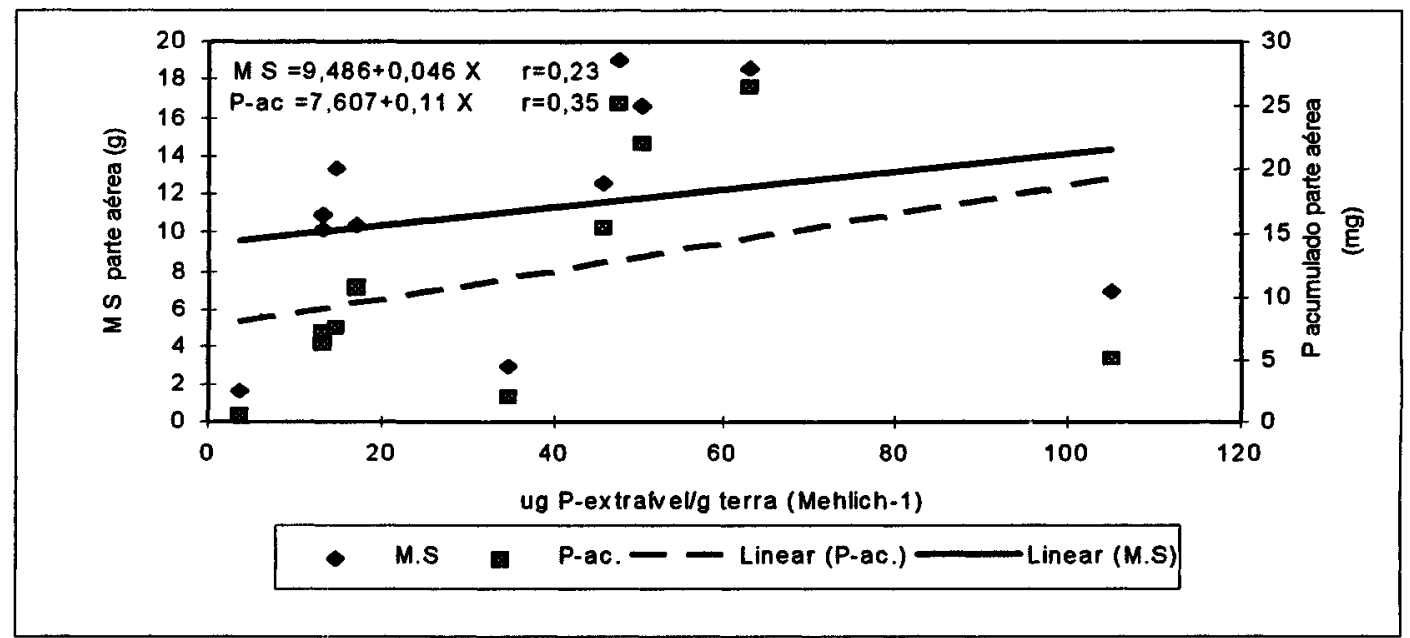

Figura 4- Relação entre produção de matéria seca (M.S) e fósforo acumulado (P-ac.) pela parte aéréa do arroz com o fósforo disponivel no solo, determinado pelo extrator Mehlich-1. 
isótopo do próprio elemento, sem a introdução de soluções salinas, complexantes ou ácidas (MURAOKA, 1991). Entretanto, esse processo pode ser afetado pelo conteúdo de bases trocáveis e por variações nas condições de equilíbrio entre solos que receberam aplicação de diferentes fontes de fósforo (CABALA-ROSAND \& SANTANA, 1981; STEFANUTTI, 1991).

O extrator Mehlich-1, numa avaliação geral com todas as fontes de fósforo, foi o que apresentou menor correlação com a produção de matéria seca e P-contido na parte aérea do arroz (Figura 4). Entretanto, ao se excluir os resultados dos tratamentos com fosfato de Araxá, as correlações anteriores aumentaram de tal modo que, para o P-acumulado, atingiram o maior valor $(r=$ 0,96), como se observa na Figura 5 . Este resultado favorece a posição da rede de laboratórios de análises de terra da maior parte do Brasil, que continua usando o extrator Mehlich-1 como método

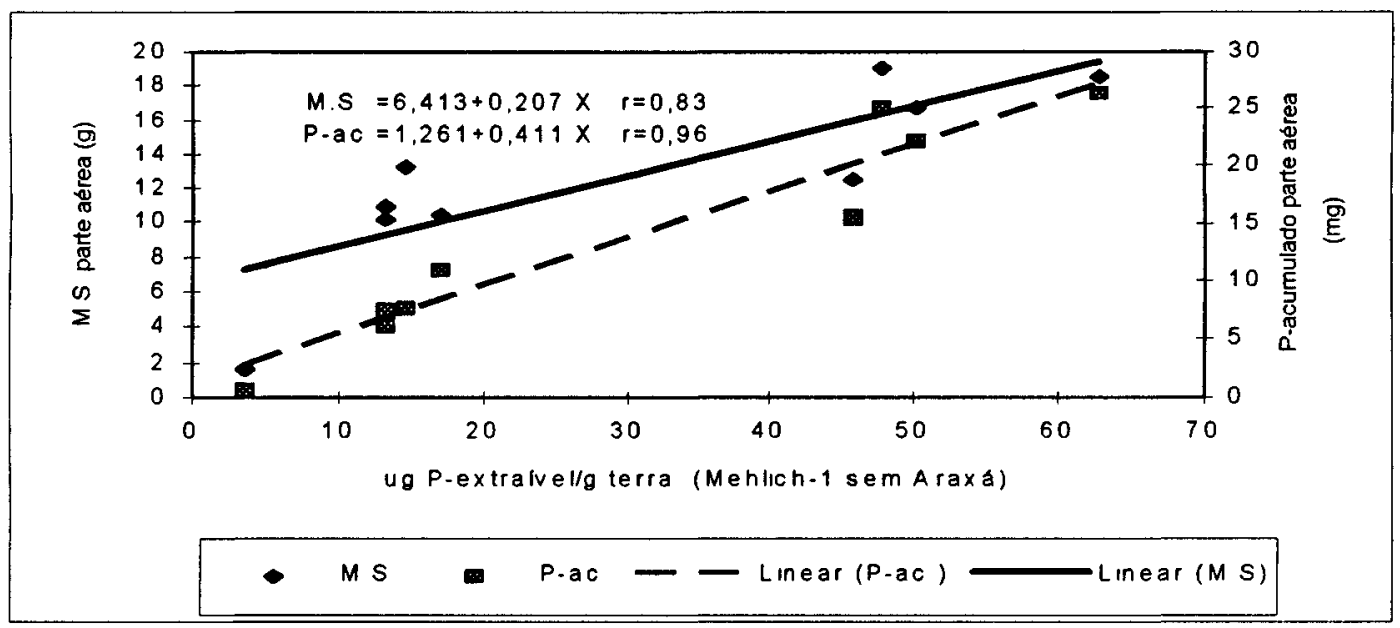

Figura 5- Relação entre produção de matéria seca (M.S) e fósforo acumulado (P.ac.) pela parte aérea do arroz com o fósforo disponivel no solo, determinado pelo extrator Mehlich-1 sem inclusão dos tratamentos com fosfato de araxá.

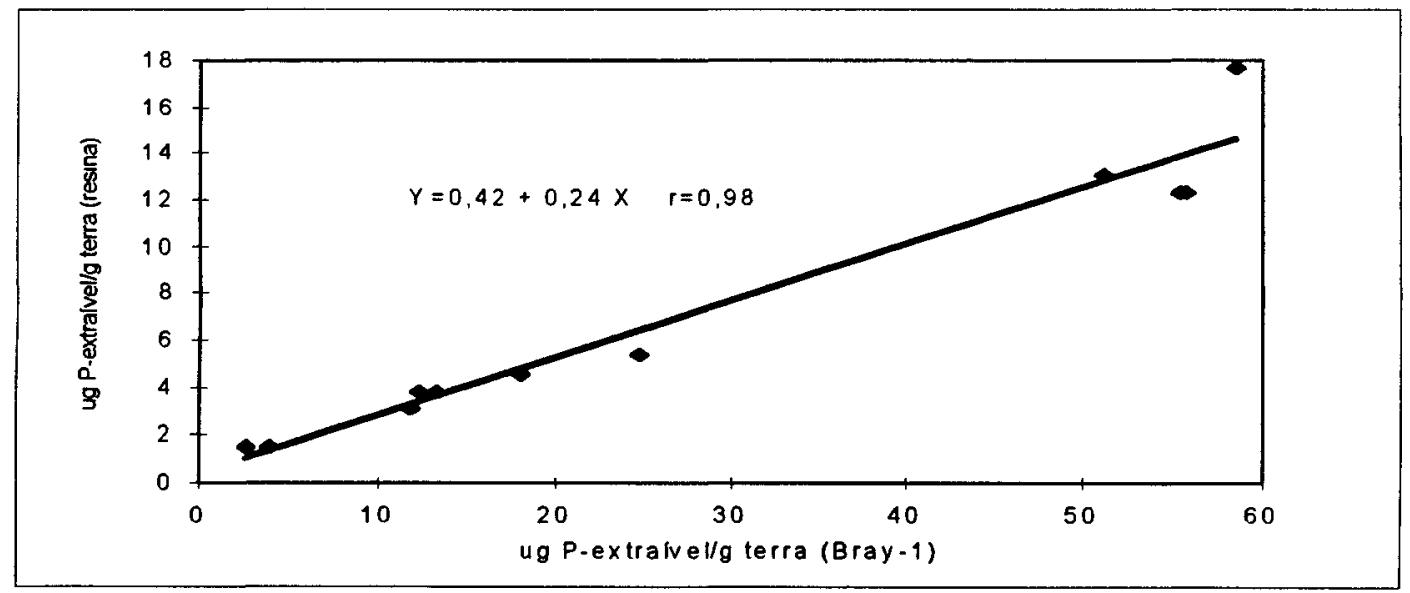

Figura 6- Relação entre o fósforo disponivel no solo determinado pelo extrator Bray-1 e o determinado pelo método da resina. 
de avaliação do P-disponível, com resultado satisfatório sob condições de fertilidade natural do solo ou quando do uso de adubos fosfatados solúveis (CABALA-ROSAND \& SANTANA, 1981; GALRÃO \& VOLKWEISS, 1981).

Correlacionando-se os resultados de P-extraído do solo entre os diferentes métodos, observa-se alta correlação entre os dados obtidos por Bray-1 e resina, sugerindo que o P-resina pode ser estimado com segurança através de determinação pelo extrator Bray-1 (Figura 6). 0 extrator Mehlich-1 não apresentou boa correlação com qualquer dos outros métodos; o valor " $\mathrm{E}$ " se correlacionou bem com o P-resina e Bray-1, tendo, porém, inconveniências para uso em rotina, além da baixa eficiência em avaliar o P-disponível, conforme demonstrado.

\section{CONCLUSÕES}

1 - Os métodos de extração que melhor expressaram os teores de fósforo no solo disponíveis para as plantas foram Bray-1 e resina, apresentando altas correlações com a produção de matéria seca da parte aérea e com o acúmulo de fósforo pelo arroz.

2 - O fósforo disponível, avaliado pelo extrator Mehlich-1, apresentou alta correlação com a produção de matéria seca e com o fósforo acumulado, quando não foram considerados os tratamentos com fosfato de Araxá.

3 - Dentre os extratores experimentados, os que apresentaram melhor correlação entre si, na determinação do P-disponível, foram o Bray-1 e Resina $(r=0,98)$.

\section{REFERÊNCIAS BIBLIOGRÁFICAS}

BARBOSA FILHO, M.A.; KINJO, T,; MURAOKA, T. Relações entre fósforo “extraível”, frações inorgânicas de fósforo e crescimento do arroz em função de fontes de fósforo, calagem e tempo de incubação. Revista Brasileira de Ciencia do Solo, v.11, p.147-55, 1987.

BOWMAN, R.A.; OLSEN, S.R.; WATANABE, F.S. Greenhouse evaluation of residual phosphorus methods in neutral and calcareous soils. Soil Science Society of America Journal, v.42, p.451-4, 1978.

BRAY, R.H. ; KURTZ, L.T. Determination of total, organic and available forms of phosphorus in soil. Soil Science, v.59, n.1, p.39-45, 1945.
CABALA-ROSAND, P.C. ; SANTANA, M.B.M. Disponibilidade de fósforo e sua diagnose pela análise de solo. In: MESA REDONDA SOBRE ADUBAÇÃO FOSFATADA NO BRASIL, 23., Salvador: SBCS, 1981.

CABALA-ROSAND, P.C. ; WILD, A. Direct use of low grade phosphate rock Brazil as fertilizer. Effect of reaction time in soil. Plant and Soil, v.65, n.2, p.35162,1982 .

CRISANTO, T.; SUTTON, C.D. Measurement of available phosphorus content of some Spanish soils. Plant and Soil, v.39, p.399-412, 1973.

EMPRESA BRASILEIRA DE PESQUISA AGROPECUÁRIA. Serviço Nacional de Levantamento e Conservação do Solo. Manual de métodos de análise do solo. Rio de Janeiro, 1979. 282p.

GALRĀO, E.Z. ; VOLKWEISS, S.J. Disponibilidade de fósforo do solo para as plantas. Revista Brasileira de Ciência do Solo, v.5, p.11-8, 1981.

GRANDE, M.A.; CURI, N.; QUAGgIO, J.A. Disponibilidade de fósforo pelos extratores de Mehlich e resina, em solos irrigados com arroz. Revista Brasileira de Ciência do Solo, v.10, n.1, p.45-50, 1986.

LARSEN, $S$. The use of ${ }^{32} \mathrm{P}$ in studies on the uptake of phosphorus by plant. Plant and Soil, v.4, n.1, p.110, 1952.

MALAVOLTA, E.; VITTI, G.C.; OLIVEIRA, S.A. Avaliação do estado nutricional das plantas: princípios e aplicações. Piracicaba: Associação Brasileira para a Pesquisa da Potassa e do Fosfato, 1989. 201p.

MURAOKA, T. Uso de técnicas isotópicas em fertilidade do solo. In: OLIVEIRA, A.J.; GARRIDO, W.E.; ARAúJo, J.D.; LOURENÇO, S. Métodos de pesquisa em fertilidade do solo. Brasília: EMBRAPA,SEA, 1991. p.225-273.

RAJ, B. van. Seleçāo de métodos de laboratório para avaliar a disponibilidade de fósforo em solos. Revista Brasileira de Ciência do Solo,v.2, p.1-9, 1978.

RAIJ, B. van. Fertilidade do solo e adubaçāo. Piracicaba: Agronômica Ceres, Associação Brasileira para a Pesquisa da Potassa e do Fosfato, 1991. 343p.

RAIJ, B. van.; FEITOSA, C.T.; SILVA, N.M. Comparação de quatro extratores de fósforo de solos. Bragantia, v.43, p.17-29, 1984. 
RAI, B. van; QUAGGIO, J.A. Metodos de andise de solos para fins de fertilidade. Campinas: IAC, 1983. 31p. (IAC. Boletim Técnico, 81).

STEFANUTTI, R. Efeito da granulometria do termofosfato magnesiano no aproveitamento do fósforo. Piracicaba, 1991. 76p. Dissertaçūo (Mestrado) - Centro de Energia Nuclear na Agricultura, Universidade de Săo Paulo.

SILVA, J.T.A. ;BRAGA, J.M. Sensibilidade de extratores de fóforo e nível crítico de dez solos do Estado de Minas Gerais. Revista Ceres, v.39, n.226, p.542-53, 1992.
TANAKA, R.T.; BAHIA, V.G.; COELHO, A.M.; FREIRE, J.C. Seleção de extratores de fósforo do solo em função das respostas das plantas de milho (Zea mays L.) e da adubação com fosfato de Patos de Minas em condiçōes de casa de vegetação. Revista Brasileira de Ciencia do Solo, v.5, p.38-42, 1981.

Recebido para publicação em 18.05 .95 Aceito para publicação em 14.08.95 